\title{
Estimating Attributable Mortality Due to Nosocomial Infections Acquired in Intensive Care Units
}

\author{
Jean-Marie Januel, MPH, RN; Stephan Harbarth, MD, MS; Robert Allard, MD, MSc; Nicolas Voirin, MSc; \\ Alain Lepape, MD; Bernard Allaouchiche, MD, PhD; Claude Guerin, MD, PhD; Jean-Jacques Lehot, MD, PhD; \\ Marc-Olivier Robert, MD, PhD; Gérard Fournier, MD; Didier Jacques, MD; Dominique Chassard, MD, PhD; \\ Pierre-Yves Gueugniaud, MD, PhD; François Artru, MD; Paul Petit, MD; Dominique Robert, MD; \\ Ismaël Mohammedi, MD; Raphaëlle Girard, MD; Jean-Charles Cêtre, MD; Marie-Christine Nicolle, MD; \\ Jacqueline Grando, MD; Jacques Fabry, MD; Philippe Vanhems, MD, PhD
}

\begin{abstract}
BACKGROUND. The strength of the association between intensive care unit (ICU)-acquired nosocomial infections (NIs) and mortality
\end{abstract} might differ according to the methodological approach taken.

ов јестіve. To assess the association between ICU-acquired NIs and mortality using the concept of population-attributable fraction (PAF) for patient deaths caused by ICU-acquired NIs in a large cohort of critically ill patients.

SetTing. Eleven ICUs of a French university hospital.

DESIGN. We analyzed surveillance data on ICU-acquired NIs collected prospectively during the period from 1995 through 2003 . The primary outcome was mortality from ICU-acquired NI stratified by site of infection. A matched-pair, case-control study was performed. Each patient who died before ICU discharge was defined as a case patient, and each patient who survived to ICU discharge was defined as a control patient. The PAF was calculated after adjustment for confounders by use of conditional logistic regression analysis.

RESUlts. Among 8,068 ICU patients, a total of 1,725 deceased patients were successfully matched with 1,725 control patients. The adjusted PAF due to ICU-acquired NI for patients who died before ICU discharge was $14.6 \%$ (95\% confidence interval [CI], 14.4\%-14.8\%). Stratified by the type of infection, the PAF was 6.1\% (95\% CI, 5.7\%-6.5\%) for pulmonary infection, 3.2\% (95\% CI, 2.8\%-3.5\%) for central venous catheter infection, $1.7 \%(95 \%$ CI, $0.9 \%-2.5 \%)$ for bloodstream infection, and $0.0 \%(95 \%$ CI, $-0.4 \%$ to $0.4 \%)$ for urinary tract infection.

CONCLUSIONS. ICU-acquired NI had an important effect on mortality. However, the statistical association between ICU-acquired NI and mortality tended to be less pronounced in findings based on the PAF than in study findings based on estimates of relative risk. Therefore, the choice of methods does matter when the burden of NI needs to be assessed.

Infect Control Hosp Epidemiol 2010; 31:000-000

Intensive care unit (ICU)-acquired nosocomial infections (NIs) are thought to increase patient mortality. ${ }^{1-3}$ However, the magnitude of this effect remains controversial and depends on study design, type of infection, and target population. ${ }^{4-12}$ Previous investigations have reported mortality estimates related to ICU-acquired NI of $4 \%-50 \% .^{1-6,9,10}$ The corresponding relative risks of death due to ICU-acquired NI were 1.4-4.0, and the corresponding odds ratios were 1.7$3.2 .^{3,4,8-12}$

The population-attributable fraction (PAF) of death is a well-known public health concept, defined as "the fraction of patients that would not have died if exposure had not occurred."13 Various epidemiologic methods can be used to evaluate the PAF, including expert assessment of case series. In contrast to the rich literature available in the field of chronic disease epidemiology, controlled studies aiming to determine the proportion of hospital deaths attributable to NI are both rare and insufficient for the calculation of stable estimates. ${ }^{14,15}$ Furthermore, several methodological issues have to be considered, since the causal relationship between

From the Laboratory of Biometry and Evolutionary Biology, CNRS, UMR 5558, Claude Bernard University of Lyon (J.-M.J., N.V., J.F., P.V.), the Intensive Care Units (A.L., B.A., C.G., J.-L.L., M.-O.R., G.F., D.J., D.C., P.-Y.G., F.A., P.P., D.R., I.M.), the Infection Control Units (R.G., J.-C.C., M.-C.N., J.G.), and the Department of Epidemiology, Hygiene and Prevention, Edouard Herriot Hospital, Hospices Civils of Lyon, University Hospital (J.F., P.V.), Lyon, France; the Health Care Evaluation Unit, Institute of Social and Preventive Medicine, University of Lausanne, University Hospital Centre of Vaud, Lausanne (J.-M.J.) and the Infection Control Program, Geneva University Hospitals and Medical School, Geneva (S.H.), Switzerland; and the Department of Social and Preventive Medicine, Public Health Unit, Infectious Diseases Centre, Montreal, Quebec, Canada (R.A.).

Received June 2, 2009; accepted September 3, 2009; electronically published February 15, 2010.

(C) 2010 by The Society for Healthcare Epidemiology of America. All rights reserved. 0899-823X/2010/3104-00XX\$15.00. DOI: 10.1086/650754 
TABLE 1. Characteristics of Intensive Care Unit Patients Excluded from and Included in the Study

\begin{tabular}{|c|c|c|c|c|c|c|c|}
\hline \multirow[b]{2}{*}{ Characteristic } & \multirow[b]{2}{*}{$\begin{array}{c}\text { Excluded } \\
\text { patients } \\
(n=4,178 \\
[34.1 \%])\end{array}$} & \multicolumn{6}{|c|}{ Included patients } \\
\hline & & $\begin{array}{c}\text { Unexposed } \\
\text { patients } \\
(n=6,391 \\
[52.2 \%])\end{array}$ & $P^{\mathrm{a}}$ & $\begin{array}{c}\text { Exposed } \\
\text { patients } \\
(n=1,677 \\
[13.7 \%])\end{array}$ & $P^{\mathrm{a}}$ & $\begin{array}{l}\text { All included } \\
\text { patients } \\
(n=8,068 \\
[65.9 \%])\end{array}$ & $P^{\mathrm{a}}$ \\
\hline Male sex & $2,453(58.7)$ & $4,193(65.6)$ & .001 & $1,071(63.9)$ & .001 & $5,264(65.2)$ & .001 \\
\hline Age, years & $57.4 \pm 19.3$ & $58.5 \pm 17.5$ & .005 & $58.7 \pm 17.6$ & .025 & $58.5 \pm 17.5$ & .002 \\
\hline Length of stay, days & $5.2 \pm 4.5$ & $7.8 \pm 6.0$ & .001 & $15.5 \pm 7.6$ & .001 & $9.4 \pm 7.1$ & .001 \\
\hline Died before discharge & $363(8.7)$ & $1,279(20.0)$ & .001 & $556(33.2)$ & .001 & $1,835(22.7)$ & .001 \\
\hline Immunocompromised & $448(10.7)$ & $1,112(17.4)$ & .001 & $245(14.6)$ & .001 & $1,357(16.8)$ & .001 \\
\hline SAPS II & $30.6 \pm 15.2$ & $39.3 \pm 18.1$ & .001 & $43.1 \pm 17.0$ & .001 & $40.1 \pm 17.9$ & .001 \\
\hline
\end{tabular}

exposure (to a pathogen that causes NI) and death can be jeopardized by multiple confounders and biases, such as severity of the underlying illness and the infection type. ${ }^{1,2,10}$ In addition, small sample size can be associated with statistical power inadequate to generate meaningful PAF estimates. ${ }^{16}$

The objective of this case-control study was to provide accurate estimates of the adjusted PAF of ICU-acquired NI in a large cohort of critically ill patients.

\section{METHODS}

\section{Patients and Setting}

Our study was based on data collected prospectively by a nosocomial infection surveillance network ${ }^{17,18}$ during the period from January 1, 1995, through December 31, 2003, from 11 adult ICUs at the University Hospital of Lyon, France.

\section{Design}

A case-control study with individual pair matching was undertaken according to the approach proposed by Bruzzi et al. ${ }^{19}$ Case patients were patients who died before ICU discharge, whereas control patients were patients who survived to discharge. For each case patient, 1 control patient from the same ICU was selected and matched according to the following criteria: sex, age (stratified into 7 age groups), and year of admission. If multiple control patients were available, the one with the date of admission closest to that of the case patient was retained. The following variables were collected and analyzed as potential confounders: Simplified Acute Physiology Score at ICU admission, immunodepression, and type of condition at admission (medical, surgical, or trauma). ${ }^{20,21}$ All variables were collected according to the criteria of a standardized and validated protocol, established by an ICU surveillance network in France. ${ }^{17,18}$

\section{Definitions of ICU-Acquired NI}

We defined various risk levels of patient death before discharge from the ICU according to exposures to ICU-acquired
NI. Exposure was defined as the presence of at least one ICUacquired NI in a given patient, ascertained according to a standardized protocol and established guidelines. ${ }^{17,18,22,23}$ ICUacquired NI was defined as infection that occurred at least 48 hours after admission to the ICU, determined on the basis of clinical and microbiological criteria. ${ }^{17,18,22,23}$ The 4 types of ICU-acquired NI considered for analysis were pulmonary infections, central venous catheter (CVC) infections, urinary tract infections (UTIs), and bloodstream infections (BSIs). For each patient, only the first infection in any of these 4 sites was analyzed. We calculated the incidence of ICU-acquired NI as the number of cases of ICU-acquired NI per 100 patients per period (period was the duration of the stay in the hospital).

We stratified analysis by type of infection and number of infected sites. To further explore the complex association between ICU-acquired NI and death in the ICU, we fitted 5 different models, stratified by type of infection and number of infected sites (see Appendix, Table A). The first model included any type of infection during the ICU stay that occurred in any of the 4 body sites. For this model, only the first ICU-acquired NI for each patient was taken into account. The other 4 subgroup models dealt with each type of ICUacquired NI separately. For each of these models, patients with ICU-acquired NI at only 1 specific, primary site were compared with a patient group without ICU-acquired NI (no infection), with a group who had at least 1 ICU-acquired NI at the primary site with coinfection at 1 or more of the 3 other sites, and finally with a group of patients who had ICUacquired NI at 1 or more of the 3 other sites but no infection at the primary site.

\section{Statistical Analysis}

We used the McNemar test to compare proportions and the paired Student $t$ test to compare means. Calculation of the crude PAF of deaths related to ICU-acquired NI was based on the following equation using the relative odds of death $(\mathrm{ROD}):^{24}$ 


$$
\mathrm{PAF}=\mathrm{CF}_{E} \times[(\mathrm{ROD}-1) / \mathrm{ROD}],
$$

where $\mathrm{CF}_{E}$ is the case patient fraction exposed to ICU-acquired NI and $[(\mathrm{ROD}-1) / \mathrm{ROD}]$ is the etiological fraction of attributable risk for case patients to be exposed at least once to ICU-acquired NI.

To perform multivariate analysis and generate an adjusted estimate of the PAF of death due to ICU-acquired NI, we determined the PAF for multiple levels of exposure. An exposure was defined as, for example, the presence in the ICU of 1 patient with 1 pulmonary infection or 1 patient with 1 UTI. Then, to assess the sum of category-specific attributable fractions, we used the following equation: $:^{25-27}$

$$
\begin{aligned}
\mathrm{PAF}= & 1-\left[\mathrm{CF}_{\mathrm{E} 1}\left(1 / \mathrm{ROD}_{1}\right)\right. \\
& \left.+\mathrm{CF}_{\mathrm{E} 2}\left(1 / \mathrm{ROD}_{2}\right)+\mathrm{CF}_{\mathrm{E} 3}\left(1 / \mathrm{ROD}_{3}\right)\right],
\end{aligned}
$$

where $\mathrm{CF}_{\mathrm{E} 1}, \mathrm{CF}_{\mathrm{E} 2}$, and $\mathrm{CF}_{\mathrm{E} 3}$ are the exposure incidence in case patients according to the different levels of exposure. The quantities $\mathrm{ROD}_{1}, \mathrm{ROD}_{2}$, and $\mathrm{ROD}_{3}$ are the different RODs according to the levels of exposure and type of ICU-acquired NI (see above).

We computed the adjusted RODs and $95 \%$ confidence intervals (CIs) with conditional multiple logistic regression models. ${ }^{28,29}$ We incorporated different terms for the specific ICU-acquired NI in the 5 models corresponding to different polytomous "risk levels" of infection (see Appendix, Table A). All covariates that reached a statistical threshold $(P<$ .10) in univariate analysis were included in a multivariable model. All analyses were performed with SPSS for Windows, version 10.1 (SPSS).

\section{RES ULTS}

A total of 12,246 patients in 11 ICUs were registered in the surveillance network during the study period. We excluded all patients with incomplete data, leaving 8,068 potentially eligible patients for analysis. The main reason for exclusion was that data were missing for reliable assessment of the presence or absence of ICU-acquired NI. The distribution of missing data was as follows: 24 patients $(0.2 \%)$ with missing information on possible pulmonary infection, 4,137 patients (33.8\%) without information on CVC infection, 56 patients $(0.5 \%)$ without information on UTI, and 28 patients $(0.2 \%)$ without information on BSI. In total, data were missing for 4,178 patients $(34.1 \%)$. Table 1 compares characteristics between included and excluded patients.

Among the 8,068 patients included in the study, the total incidence of ICU-acquired NI was $20.8 \%$ during the study period (annual range, $16.7 \%$ [in 2003] to $25.6 \%$ [in 1996]; $P<.001)$. The range in total incidence among the different ICUs was $6.3 \%-29.6 \%(P<.001)$. The mean annual incidence was $8.0 \%$ for pulmonary infection, $7.9 \%$ for CVC infection, $7.6 \%$ for UTI, and $3.3 \%$ for BSI. During the study period, 1,835 patients (22.7\%) died before ICU discharge.
The crude mortality rate was $33.2 \%$ (556 of 1,677$)$ for patients who had contracted at least 1 ICU-acquired NI and 20.0\% $(1,279$ of 6,391$)$ for patients without ICU-acquired NI during their stay $(P<.001)$.

Overall, 1,725 case patients were successfully matched to 1,725 control patients (total $n=3,450$ ) for the final analysis. These 1,725 deceased patients represented $94 \%$ of all deceased subjects from the source population of our study. Case patients and control patients differed by mean length of stay $(P=.031)$, mean Simplified Acute Physiology Score II $(P<.001)$, immunocompromised status $(P<.001)$, and type of admission conditions $(P<.001)$ (Table 2$)$. During the study period, the incidence of ICU-acquired NI was $31.0 \%$ for case patients and $19.5 \%$ for the control patients $(P<$ $.001)$.

\section{Attributable Mortality Due to ICU-Acquired NI}

Table 3 presents crude and adjusted ROD in patients who experienced at least 1 ICU-acquired NI. Each model provides an estimate of the PAF for ICU mortality that relates to ICUacquired NI, stratified by type of infection and the number of infected sites. The PAF for each of the 5 models of ICUacquired NI is reported in Table 4. The PAF due to ICUacquired NI in patients who died before ICU discharge was $14.6 \%$ (95\% CI, $14.4 \%-14.8 \%$ ), which means that of 100 deaths that occurred before ICU discharge, 14.6 were related to an ICU-acquired NI. Stratified by type of infection, the PAFs were $6.1 \%$ (95\% CI, 5.7\%-6.5\%) for pulmonary infection, 3.2\% (95\% CI, $2.8 \%-3.5 \%)$ for CVC infection, and $1.7 \%(95 \%$ CI, $0.9 \%-2.5 \%)$ for BSI. No significant proportion of deaths was attributable to UTI when it was the patient's only infected site (PAF, 0.0 [ $95 \% \mathrm{CI},-0.4 \%$ to $0.4 \%]$ ). Under the assumption of the additive property of the statistical model used, the sum of all infection-specific PAF values was equal to the global PAF presented in model 1.25-27

TABle 2. Entry Characteristics of Case Patients Who Died before Dischange and Matched Control Patients Who Survived to Discharge in 11 Intensive Care Units (ICUs) at the University Hospital of Lyon, 1995-2003

\begin{tabular}{lccr}
\hline & $\begin{array}{c}\text { Case } \\
\text { patients } \\
(n=1,725)\end{array}$ & $\begin{array}{c}\text { Control } \\
\text { patients } \\
(n=1,725)\end{array}$ & $P^{\text {a }}$ \\
Characteristic & $9.6 \pm 7.1$ & $10.1 \pm 7.3$ & .031 \\
Length of ICU stay, days & $52.4 \pm 18.5$ & $38.5 \pm 16.2$ & $<.001$ \\
SAPS II & $314(18.2)$ & $258(15.0)$ & $<.001$ \\
Immunocompromised & & & $<.001$ \\
Admission condition & $435(25.2)$ & $565(32.8)$ & \\
$\quad$ Medical & $1,079(62.6)$ & $892(51.7)$ & \\
$\quad$ Surgical & $211(12.2)$ & $268(15.5)$ & \\
Trauma &
\end{tabular}

NOTE. Values are expressed as no. (\%) for qualitative variables and as mean \pm standard deviation (SD) for quantitative variables. SAPS II, Simplified Acute Physiology Score.

${ }^{a}$ The McNemar test was used to compare categorical variables, and the paired Student $t$ test was used to compare continuous variables. 
TA в LE 3. Relative Odds of Death (ROD) in Relation to Different Risk Levels of Intensive Care Unit (ICU)-Acquired Nosocomial Infections (NIs) using Conditional Logistic Regression Models at 11 Intensive Care Units at the University Hospital of Lyon, 1995-2003

\begin{tabular}{|c|c|c|c|c|}
\hline \multirow[b]{2}{*}{ Risk levels of ICU-acquired NI } & \multicolumn{2}{|c|}{ Crude ROD } & \multicolumn{2}{|c|}{ Adjusted ROD } \\
\hline & $\operatorname{ROR}(95 \% \mathrm{CI})$ & $P$ & ROR (95\% CI) & $P$ \\
\hline \multicolumn{5}{|l|}{ Model 1} \\
\hline No infection & 1.0 & & 1.0 & \\
\hline At least 1 pulmonary infection, CVC infection, UTI, or BSI & $1.9(1.6-2.2)$ & $<.001$ & $1.9^{\mathrm{a}}(2.0-3.1)$ & $<.001$ \\
\hline \multicolumn{5}{|l|}{ Model 2} \\
\hline No infection & 1.0 & & 1.0 & \\
\hline Only 1 pulmonary infection & $3.1(2.2-4.20)$ & $<.001$ & $3.3(2.2-4.8)$ & $<.001$ \\
\hline Pulmonary infection and at least 1 other infected site & $3.3(2.2-4.7)$ & $<.001$ & $3.3(2.1-5.1)$ & $<.001$ \\
\hline At least 1 other infected site, pulmonary infection excluded & $1.4(1.1-1.6)$ & .002 & $1.4(1.1-1.7)$ & $<.001$ \\
\hline \multicolumn{5}{|l|}{ Model 3} \\
\hline No infection & 1.0 & & 1.0 & \\
\hline Only 1 CVC infection & $1.8(1.3-2.4)$ & $<.001$ & $1.8(1.3-2.5)$ & $<.001$ \\
\hline CVC infection and at least 1 other infected site & $2.4(1.6-3.4)$ & $<.001$ & $2.2(1.4-3.4)$ & $<.001$ \\
\hline At least 1 other infected site, CVC infection excluded & $1.8(1.5-2.2)$ & $<.001$ & $1.9(1.5-2.4)$ & $<.001$ \\
\hline \multicolumn{5}{|l|}{ Model 4} \\
\hline No infection & 1.0 & & 1.0 & \\
\hline Only 1 UTI & $0.8(0.6-1.1)$ & .205 & $1.0(0.6-1.3)$ & .598 \\
\hline UTI and at least 1 other infected site & $1.6(1.1-2.3)$ & .011 & $1.9(1.2-2.9)$ & $<.001$ \\
\hline At least 1 other infected site, UTI excluded & $2.6(2.1-3.1)$ & $<.001$ & $2.5(1.9-3.2)$ & $<.001$ \\
\hline \multicolumn{5}{|l|}{ Model 5} \\
\hline No infection & 1.0 & & 1.0 & \\
\hline Only 1 BSI & $3.5(1.9-6.8)$ & $<.001$ & $3.9(1.7-8.7)$ & $<.001$ \\
\hline BSI and at least 1 other infected site & $1.9(1.3-2.9)$ & .001 & $2.0(1.2-3.3)$ & $<.001$ \\
\hline At least 1 other infected site, BSI excluded & $1.8(1.5-2.1)$ & $<.001$ & $1.8(1.5-2.3)$ & $<.001$ \\
\hline
\end{tabular}

Note. Adjusted on Simplified Acute Physiology Score II (SAPS) as categorical variable, immunocompromised status as dichotomous variable, and type of admission condition as categorical variable. BSI, bloodstream infection; CI, confidence interval; CVC, central venous catheter; ROR, relative odds ratio; UTI, urinary tract infection.

${ }^{a}$ The ROD is increased by 1.9 in case patients who experienced at least 1 ICU-acquired NI, compared with case patients who did not.

\section{I S C USS I O N}

The objective of this study was to estimate the PAF for patient deaths due to infection acquired before ICU discharge. The 3 major findings of this study were as follows: First, 14.6\% of deaths (95\% CI, $14.4 \%-14.8 \%)$ might be attributed to ICU-acquired NI. Second, to estimate mortality attributable to ICU-acquired NI, it may be clinically useful and complementary to other, commonly risk-based, methods to use the PAF concept. Third, exposure to ICU-acquired NI was an important determinant of death in our population.

The proportion of deaths attributable to ICU-acquired NI was likely associated with the incidence of exposure to infections rather than with the ROD associated with the level of infection. Therefore, the incidence of exposure to infections was far more relevant than only the risk of infection by itself. Because we analyzed attributable risk, in order to find the effect of ICU-acquired NI on mortality, it was more appropriate to study the effect of incidence of infections than to study the effect of risk of infection. For example, the ratio of the ROD of 3.3 for pulmonary infection only (Table 4) to the ROD of 1.4 for at least 1 infected site, pulmonary infection excluded, was 2.4. In contrast, the number of deaths attributable only to PI was $6.1 \%$ (95\% CI, 5.7\%-6.5\%) and the number of deaths attributable to at least 1 infected site, PI excluded, was $4.6 \%$ (95\% CI, 4.3\%-4.9\%) (Table 4 ), so the ratio of deaths attributable only to PI to deaths attributable to at least 1 infected site, PI excluded, was only 1.3. This lower ratio was due to computation of the death attributable proportion, which was taken into account for the incidence of exposure for case patients. The incidence of exposure to only pulmonary infection was $8.7 \%$, compared with $15.9 \%$ for at least 1 infected site, pulmonary infection excluded. This finding is an interesting contribution of this study, ${ }^{30-32}$ which underscores the fact that a difference exists between the risk for an event to occur (ie, excess risk) and the attributable risk for the same event, depending on the incidence of exposure to risk factors for that event. In theory, odds is the ratio of the probability that an event of interest occurs to the probability that it does not occur (in contrast, risk is the probability for an event to occur within an exposed population), ${ }^{33,34}$ while an attributable event refers to how many events are the direct consequence of an exposure. ${ }^{34}$ This 
TA B LE 4. Population-Attributable Fraction (PAF) of Deaths According to Different Risk Levels of Intensive Care Unit (ICU)-Acquired Nosocomial Infections (NIs) at 11 ICUs at the University Hospital of Lyon, 1995-2003

\begin{tabular}{|c|c|c|}
\hline Risk level of ICU-acquired NI & $\mathrm{CF}_{E}, \%$ & PAF, \% (95\% CI) \\
\hline \multicolumn{3}{|l|}{ Model 1} \\
\hline At least 1 pulmonary infection, CVC infection, UTI, or BSI & 31.0 & $14.6(14.4-14.8)$ \\
\hline \multicolumn{3}{|l|}{ Model 2} \\
\hline Only 1 pulmonary infection & 8.7 & $6.1(5.7-6.5)$ \\
\hline Pulmonary infection and at least 1 other infected site & 6.4 & $4.5(4.0-5.0)$ \\
\hline At least 1 other infected site, pulmonary infection excluded & 15.9 & $4.6(4.3-4.9)$ \\
\hline \multicolumn{3}{|l|}{ Model 3} \\
\hline Only 1 CVC infection & 7.2 & $3.2(2.8-3.5)$ \\
\hline CVC infection and at least 1 other infected site & 5.3 & $2.9(2.4-3.4)$ \\
\hline At least 1 other infected site, CVC infection excluded & 18.5 & $8.7(8.4-9.1)$ \\
\hline \multicolumn{3}{|l|}{ Model 4} \\
\hline Only 1 UTI & 4.2 & $0.0(-0.4$ to 0.4$)$ \\
\hline UTI and at least 1 other infected site & 4.1 & $1.9(1.4-2.4)$ \\
\hline At least 1 other infected site, UTI excluded & 22.7 & $13.6(13.3-13.9)$ \\
\hline \multicolumn{3}{|l|}{ Model 5} \\
\hline Only 1 BSI & 2.3 & $1.7(0.9-2.5)$ \\
\hline BSI and at least 1 other infected site & 3.8 & $1.9(1.4-2.4)$ \\
\hline At least 1 other infected site, BSI excluded & 24.9 & $11.0(10.8-11.2)$ \\
\hline
\end{tabular}

NOTE. $\mathrm{PAF}=\mathrm{CF}_{E} \times[(\mathrm{ROD}-1) / \mathrm{ROD}]$, where $\mathrm{CF}_{E}$ is the case patient fraction exposed to ICU-acquired $\mathrm{NI}$ and $[(\mathrm{ROD}-1) / \mathrm{ROD}]$ is the etiological fraction of attributable risk for case patients to be exposed at least once to ICU-acquired NI. BSI, bloodstream infection; CVC, central venous catheter; UTI, urinary tract infection.

concept has not been adequately explored in the field of hospital-acquired infections, compared with other public health domains. ${ }^{35-37}$

For clinical practice, these findings could be of major interest. Table 4 reports that $14.6 \%$ (95\% CI, $14.4 \%-14.8 \%$ ) of deaths during ICU stay are attributable to ICU-acquired NI, whatever the site of infection. For pulmonary infection only or pulmonary infection with a coinfection, the proportion of deaths attributable to pulmonary infection was $10.6 \%$. For CVC infection only or CVC infection with a coinfection, the proportion of deaths attributable to CVC infection was $6.1 \%$. Interventions to reduce the mortality attributable to ICU-acquired NI should be focused on these 2 sites of infection because of their high incidence. In particular, because of their incidence and potential effect on mortality, pulmonary infections should be a primary target for interventions. A recent study has demonstrated that prevention of ventilator-associated pneumonia by means of selective digestive tract decontamination and selective oropharyngeal decontamination can reduce ICU and 28-day mortality, compared with no intervention. ${ }^{38}$ Additional and less controversial preventive measures to decrease exogenous or endogenous cross-transmission to prevent ventilator-associated pneumonia should be considered. For instance, increased compliance with hand hygiene, short duration of intubation, nonprofound sedation, and correct patient positioning may help to decrease rates of ventilator-associated pneumonia rates and ultimately to decrease the likelihood of death.

For decades, the method chosen for this study has been used in chronic disease epidemiology to examine attributable mortality. Conceptually, we assumed that the ROD was different from the total number of deaths related to an exposure, allowing estimation of the "etiological fraction," as proposed by Samore and Harbarth. ${ }^{39}$ The advantage of our method of calculating the PAF is that it takes into account multiple levels of exposure (pulmonary infection, CVC infection, UTI, and BSI). This stems from the PAF concept developed by Levin in 1953:40 when risk is multilevel (at least 2 categories), confounders are present, and risk adjustment is needed. ${ }^{26,27}$

Some limitations must be addressed. For each patient, only the first infection by site was considered for analysis. Moreover, the cumulative effect of repeated infections was not estimated. The analysis was not stratified by the causative microorganisms responsible for the infection. It was not possible to match or adjust for the causative organisms because infections were frequently polymicrobial. However, a similar study design could be used for patients infected by a specific microorganism of high clinical interest (eg, Staphylococcus aureus or Pseudomonas aeruginosa). In future studies, analysis stratified by microorganism might be helpful to identify the pathogens that are associated with the worst prognosis. ${ }^{41-43}$ Since our estimate of ROD is closer to an odds ratio than to a relative risk, the strength of association could have been overestimated. In addition, the lower incidence of death in the population that was excluded from the analysis because of missing data on ICU-acquired NI $(N=4,178)$ could have biased our results. In consequence, the true proportion of attributable deaths due to ICU-acquired NI might be lower 
than in our results. Finally, residual confounding factors cannot be excluded, owing to the design of the surveillance network, since data were collected prospectively for surveillance of ICU-acquired NI and not primarily for survival analysis.

\section{CONCLUSIONS}

In summary, the results of this study strongly suggest that an important proportion of ICU deaths was caused by NI. These results support previous evidence that death and ICU-acquired NI are causally linked, but the strength of the association may vary according to the methodological approach taken. The method reported in this study could be considered complex because it has not often been used in the field; however, the use of this method can yield additional results to illuminate a controversial issue. The incidence of exposure was a major determinant identified by use of our method. Therefore, one way to estimate the contribution of ICU-acquired NI to mortality might be based on estimation of the PAF, which takes into account the incidence of exposure to ICU-acquired NI.

\section{ACKNOWLEDGMENTS}

Financial support. Educational grant from GSK France. SHEA Travel Award to J.-M.J.

Potential conflicts of interest. All authors report no conflicts of interest relevant to this article.

\section{A P P E N D I X}

TAвLE A. Five Models, Stratified by Type of Nosocomial Infections (NIs) Acquired in the Intensive Care Unit (ICU) and Risk Levels

\begin{tabular}{ll}
\hline Risk level & Definition \\
\hline $\begin{array}{l}\text { Model 1: ICU-acquired pulmonary infection, } \\
\text { CVC infection, UTI, and/or BSI }\end{array}$ & \\
0 & No infection \\
1 & At least 1 pulmonary infection, CVC infection, UTI, or BSI \\
Model 2: ICU-acquired pulmonary infection & \\
0 & No infection \\
1 & Only 1 pulmonary infection \\
2 & Pulmonary infection and at least 1 other infected site \\
3 & At least 1 other infected site, pulmonary infection excluded \\
Model 3: ICU-acquired CVC infection & \\
0 & No infection \\
1 & Only 1 CVC infection \\
2 & CVC infection and at least 1 other infected site \\
3 & At least 1 other infected site, CVC infection excluded \\
Model 4: ICU-acquired UTI & \\
0 & No infection \\
1 & Only 1 UTI \\
3 & UTI and at least 1 other infected site \\
3 & At least 1 other infected site, UTI excluded \\
Model 5: ICU-acquired BSI & \\
0 & No infection \\
1 & Only 1 BSI \\
3 & BSI and at least 1 other infected site \\
\hline
\end{tabular}

NOTE. BSI, bloodstream infection; CVC, central venous catheter; UTI, urinary tract infection.

Address reprint requests to Jean-Marie Januel, Health Care Evaluation Unit, Institute of Social and Preventive Medicine, University of Lausanne, University Hospital Centre of Vaud, 1005 Lausanne, Switzerland (jean-marie.januel@chuv.ch).

Presented in part: 17th Annual Scientific Meeting of the Society for Healthcare Epidemiology of America; April 14-17, 2007; Baltimore, Maryland; Poster 59.

\section{REFERENCES}

1. Eggimann P, Pittet D. Infection control in the ICU. Chest 2001;120:20592093.
2. Vincent JL. Nosocomial infections in adult intensive-care units. Lancet 2003; 361:2068-2077.

3. Safdar N, Dezfulian C, Colard HR, Saint S. Clinical and economic consequences of ventilator-associated pneumonia: a systematic review. Crit Care Med 2005;33:2184-2193.

4. Girou E, Stephan F, Novara A, Safar M, Fagon JY. Risk factors and outcome of nosocomial infections: results of a matched case-control study of ICU patients. Am J Respir Crit Care Med 1998;157:1151-1158.

5. Sanchez-Velazquez LD, Ponce de Leon Rosales S, Rangel Frausto MS. The burden of nosocomial infection in intensive care unit: effects on organ failure, mortality and costs—a nested case-control study. Arch Med Res 2006;37:370375.

6. Rosenthal VD, Guzman S, Orellano PW. Nosocomial infections in medical- 
surgical intensive care units in Argentina: attributable mortality and length of stay (published correction appears in Am J Infect Control 2003;31:409). Am J Infect Control 2003;31:291-295.

7. Blot S, De Bacquer D, Hoste E, et al. Influence of matching for exposure time on estimates of attributable mortality caused by nosocomial bacteremia in critically ill patients. Infect Control Hosp Epidemiol 2005;26:352356.

8. Garrouste-Orgeas M, Timsit JF, Tafflet M, et al. Excess risk of death from intensive care unit-acquired nosocomial bloodstream infections: a reappraisal (published correction appears in Clin Infect Dis 2006;42:1818). Clin Infect Dis 2006;42:1118-1126.

9. Pittet D, Tarara D, Wenzel RP. Nosocomial bloodstream infection in critically ill patients: excess length of stay, extra costs, and attributable mortality. JAMA 1994;271:1598-1601.

10. Fagon JY, Novara A, Stephan F, Giroud E, Safar M. Mortality attributable to nosocomial infections in the ICU. Infect Control Hosp Epidemiol 1994;15: $428-434$.

11. Soufir L, Timsit JF, Mahe C, Carlet J, Regnier B, Chevret S. Attributable morbidity and mortality of catheter-related septicemia in critically ill patients: a matched, risk-adjusted, cohort study. Infect Control Hosp Epidemiol 1999;20:396-401.

12. Vincent JL, Bihari DJ, Suter PM, et al. The prevalence of nosocomial infection in intensive care units in Europe: results of the European Prevalence of Infection in Intensive Care (EPIC) study. JAMA 1995;274:639644 .

13. Rothman KJ, Greenland S. Modern Epidemiology. 2nd ed. Philadelphia, PA: Lippincott-Raven; 1998.

14. Garcia-Martin M, Lardelli-Claret P, Jiménez-Moleon JJ, Buenos-Cavanillas A, Luna-del-Castillo JD, Galvez-Vargas R. Proportion of hospital deaths potentially attributable to nosocomial infection. Infect Control Hosp Epidemiol 2001;22:708-714.

15. Fabbro-Peray P, Sotto A, Defez C, et al. Mortality attributable to nosocomial infection: a cohort of patients with and without nosocomial infection in a French university hospital. Infect Control Hosp Epidemiol 2007;28:265272.

16. Gail MH. A bibliography and comments on the use of statistical models in epidemiology in the 1980s. Stat Med 1991;10:1819-1885.

17. Savey A, Lepape A, Tressière B, Ayzac L, Fabry J. ICUs-AI for the Southeast of France. Surveillance network protocol. C. CLIN Sud-Est [in French]. http://cclin-sudest.chu-lyon.fr/Reseaux/REA/. Accessed June 2009.

18. Vanhems P, Lepape A, Savey A, Jambou P, Fabry J. Nosocomial pulmonary infection by antimicrobial-resistant bacteria of patients hospitalized in intensive care units: risk factors and survival. J Hosp Infect 2000;45:98-106.

19. Bruzzi P, Green SB, Byar DP, Brinton LA, Schairer C. Estimating the population attributable risk for multiple risk factors using case-control data. Am J Epidemiol 1985;122:904-914.

20. Le Gall JR, Loirat P, Alperovitch A, et al. A simplified acute physiology score for ICU patients. Crit Care Med 1984;12:975-977.

21. Salemi C, Morgan J, Padilla S, Morrissey R. Association between severity of illness and mortality from nosocomial infection. Am J Infect Control 1995; 23:188-193.

22. Suetens C, Savey A, Labeeuw J, Morales I; HELICS-ICU. The ICU-HELICS Programme: towards European surveillance of hospital-acquired infections in intensive care units. Euro Surveill 2002;7:127-128.
23. Gardner JS, Jarvis WR, Emori TG, Horan TC, Hughes JM. CDC definitions for nosocomial infections. In: Olmsted RN, ed. APIC Infection Control and Applied Epidemiology: Principles and Practice. St Louis, MO: Mosby; 1996: A1-A20.

24. Miettinen OS. Proportion of disease caused or prevented by a given exposure, trait or intervention. Am J Epidemiol 1974;99:325-332.

25. Wacholder S, Benichou J, Heineman EF, Hartge P, Hoover RN. Attributable risk: advantages of a broad definition of exposure. Am J Epidemiol 1994;140: 303-309.

26. Hanley JA. A heuristic approach to the formulas for population attributable fraction. J Epidemiol Community Health 2001;55:508-514.

27. Rockhill B, Newman B, Weinberg C. Use and misuse of population attributable fractions. Am J Public Health 1998;88:15-19.

28. Kuritz SJ, Landis JR. Attributable risk ratio estimation from matched-pairs case-control data. Am J Epidemiol 1987;125:324-328.

29. Kuritz SJ, Landis JR. Attributable risk estimation from matched case-control data. Biometrics 1988;44:355-367.

30. Walter SD. The estimation and interpretation of attributable risk in health research. Biometrics 1976;32:829-849.

31. Poole C. Exposure opportunity in case-control studies. Am J Epidemiol 1986;123:352-358.

32. Kuritz SJ, Landis JR. Re: "Exposure opportunity in case-control studies". Am J Epidemiol 1987;125:1095-1096.

33. Bland JM, Altman DG. The odds ratio. BMJ 2000;320:1468.

34. Kelsey JL, Whittemore AS, Evans AS, Thompson WD. Methods in observational epidemiology. 2nd ed. New York, NY: Oxford University Press; 1996.

35. Doll R, Hill AB. Smoking and carcinoma of the lung. Br Med J 1950;221: 739-748.

36. Levin MI, Goldstein H, Gerhardt PR. Cancer and tobacco smoking. J Am Med Assoc 1950;143:336-338.

37. Ezzati M, Lopez AD. Estimates of global mortality attributable to smoking in 2000. Lancet 2003;362:847-852.

38. de Smet AM, Kluytmans JA, Cooper BS, et al. Decontamination of the digestive tract and oropharynx in ICU patients. N Engl J Med 2009;360: 20-31.

39. Samore MH, Harbarth S. A methodologically focused review of the literature in hospital epidemiology and infection control. In: Mayhall CG, ed. Hospital Epidemiology and Infection Control. 3rd ed. Philadelphia, PA: Lippincott Williams \& Wilkins; 2004:1645-1657.

40. Levin ML. The occurrence of lung cancer in man. Acta Unio Int Contra Cancrum 1953;9:531-541.

41. Moalla M, Baratin D, Giard M, Vanhems P. Incidence of methicillin-resistant Staphylococcus aureus nosocomial infections in intensive care units in Lyon University hospitals, France, 2003-2006. Infect Control Hosp Epidemiol 2008;29:454-456.

42. Macgowan AP; BSAC Working Parties on Resistance Surveillance. Clinical implications of antimicrobial resistance for therapy. JAntimicrob Chemother 2008;62(Suppl 2):S105-S114.

43. Blot S, Depuydt P, Vandewoude K, De Bacquer D. Measuring the impact of multidrug resistance in nosocomial infection. Curr Opin Infect Dis 2007; 20:391-396. 